\title{
Inteligência Artificial e o Futuro do Trabalho: entre Fausto e Prometeu
}

\author{
Alexandre M. da Silva ${ }^{1}$, Dante A. C. Barone ${ }^{1}$, \\ ${ }^{1}$ Instituto de Informática - Universidade Federal do Rio Grande do Sul (UFRGS) \\ Caixa Postal 15.064 - 91.501-970 - Porto Alegre - RS - Brazil \\ \{alexandre.silva, barone\} @inf.ufrgs.br
}

\begin{abstract}
The history of automation, marked mainly by the four industrial revolutions, increases a markedly dichotomous discussion on the effect of technology on the world of work. This article presents an analysis of the two poles of this debate based on the theories of cyberculture. The result of our analysis shows the need for a more integrated view on the subject, given the complexity of the relationships that are established in the current stage of technological developments of our Society through Artificial Intelligence and other technologies.
\end{abstract}

Resumo. A história da automação, marcada sobretudo pelas quatro revoluções industriais, fomenta uma discussão marcadamente dicotômica sobre o efeito da tecnologia no mundo do trabalho. Este artigo apresenta uma análise sobre os dois polos deste debate a partir das teorias da cibercultura. $O$ resultado de nossa análise mostra a necessidade de uma visão mais integradora sobre o assunto, dada a complexidade das relações que se estabelecem no estágio atual do desenvolvimento tecnológico da nossa Sociedade por meio da Inteligência Artificial e outras tecnologias.

\section{Introdução}

As primeiras concepções de Inteligência Artificial têm sua origem nas narrativas mitológicas das civilizações antigas, na Filosofia e no desenvolvimento da Lógica Formal e da Matemática. Anterior à invenção dos computadores, os entes autônomos capazes de reproduzir as ações humanas já estavam presentes na Cultura [Evans 2013]. Assim, podemos afirmar que a gênese do desenvolvimento daquilo que hoje conhecemos como o campo da Inteligência Artificial está presente ao longo da História da Sociedade Ocidental.

O termo "Inteligência Artificial" é utilizado pela primeira vez por John McCarthy [Taulli 2019]. McCarthy é considerado o pai da Inteligência Artificial Moderna e organizador da primeira conferência sobre o assunto no Dartmouth College em 1956 [Evans 2013]. Para McCarthy o objetivo da Inteligência Artificial era "desenvolver máquinas que se [comportassem] como se fossem inteligentes" [Ertel 2017].

Para Rüdiger (2013) “os pensadores da técnica podem, em geral, ser divididos em prometeicos e fáusticos", pois este par mítico exemplifica a inquietação entre otimistas e pessimistas, respectivamente. Aqueles que se identificam com a virtude da técnica vislumbram o progresso, a emancipação e o benefício proporcionados pelos 
“artefatos tecnológicos". Numa visão minoritária, por outro lado, estão aqueles que julgam o peso das mudanças tecnológicas como algo prejudicial à Sociedade [Rüdiger 2013]. Devido ao caráter disruptivo da Inteligência Artificial, inúmeras são as mudanças e consequentemente, as preocupações na Sociedade, sobretudo no campo laboral [Dignum 2019].

Este artigo analisa as mudanças provocadas no mundo do trabalho, a partir da evolução da Inteligência Artificial no contexto da quarta revolução industrial. A seção 2 descreve brevemente a visão utópico-prometeica e a visão distópico-fáustica. Em seguida, na seção 3, analisamos algumas das visões acerca da Inteligência Artificial e a sua influência no mundo do trabalho. As conclusões preliminares são apresentadas na seção 4, assim como as sugestões de futuras pesquisas sobre o tema. Entre as visões apresentadas há muitas outras possibilidades, portanto, é nosso objetivo considerar a validade apenas dos dois polos aqui apresentados em contraponto. Busca-se, por meio destas duas visões, por vezes, antagônicas, delimitar o campo de discussão sobre o futuro do trabalho em meio à rápida e pujante evolução tecnológica.

\section{Principais conceitos}

\subsection{As quatro revoluções industriais e a Sociedade 5.0}

Para Roncati et al. (2018), a revolução industrial não representa apenas o desenvolvimento tecnológico. Além da técnica em si, experimenta-se uma maior produtividade, bem como uma ruptura que traz uma nova visão de mundo que consolida o capitalismo.

A quarta revolução industrial reúne a inteligência Artificial, a Robótica, a Internet das Coisas e a Computação Quântica, além de outras tecnologias capazes de aumentar a produtividade [Sako 2020]. Esta revolução é marcada de sobremaneira pela velocidade na qual ocorrem as mudanças [Roncati et al. 2018].

A primeira revolução industrial (1760) teve como marco as inovações introduzidas, principalmente, pela máquina a vapor [Roncati 2018] e possibilitou a mecanização da produção [Sako 2020]. Em seguida com a disseminação da eletricidade, ocorreu a segunda revolução industrial (século XIX) como assinala Roncati (2018). Além da eletricidade, o uso dos princípios científicos alavancou a produção em massa [Sako 2020]. Já a terceira revolução industrial (segunda metade do século XX) está mais estreitamente ligada ao processo de Globalização, proporcionando uma visão "arrojada e futurista", por meio de máquinas, robôs ${ }^{1}$ e processos auxiliados por computador, conforme asseveram Silva et al. (2002). Neste cenário uma série de tarefas rotineiras passa a ser automatizada com o uso da computação [Sako 2020].

Com o avanço tecnológico e a velocidade das mudanças destacadas na quarta revolução industrial, estamos frente à denominada Sociedade 5.0, uma revolução que

\footnotetext{
${ }^{1}$ Na peça do escritor tcheco Karel Tchápek (1890-1938), um cientista descobre uma maneira de dar vida às máquinas. Isso ocasiona uma desregulação nos modos de produção e torna a mão de obra tradicional obsoleta. As criaturas desenvolvidas pelo cientista não possuem sentimentos ou outras características humanas essenciais. A palavra "robô", cunhada pela primeira vez nesta obra, em tcheco significa "escravidão, trabalho forçado ou servidão", tendo sido incorporada à maioria dos idiomas [Tchápek 2012].
} 
tem por objetivo "desenvolver serviços que melhorem a vida das pessoas, de uma forma sustentável e adaptável” [Merluzzi 2019]. Assim, são esperadas soluções para doenças, envelhecimento e catástrofes entre outras. Neste ínterim entre a consolidação da quarta revolução industrial da sociedade informacional e o advento da Sociedade 5.0 há grandes expectativas no que se refere ao uso massivo de tecnologia como a Inteligência Artificial.

\subsection{Cibercultura}

Segundo Rüdiger (2013), a cibercultura é "uma formação histórica de cunho prático e cotidiano, cujas linhas de força e rápida expansão (...)" estão alicerçadas sobre as redes de computadores. Segundo o mesmo autor este movimento gera "um campo de interrogação intelectual pujante, dividido em várias tendências e interpretações" [Rüdiger 2013]. Assim, aduz Rüdiger (2013) "a transformação dos novos aparatos de pessoas e instituições" se tornaram ubíquos. O uso rotineiro dos recursos tecnológicos permeados pelas redes é o que podemos denominar de cibercultura. Este uso nos insere num novo mundo, o ciberespaço.

Conforme leciona Rüdiger (2013), a cibercultura se expande na medida em que a tecnologia e o capital proporcionam aparatos digitais que podem ser consumidos pelas massas. Por isso, ensina o mesmo autor, "a reconstrução das perspectivas teóricas de conceituação e entendimento da cibercultura segue um viés histórico e conceitual".

Para Levy (2010) a cibercultura designa "o conjunto de técnicas (materiais e intelectuais), de práticas, de atitudes, de modos de pensamento e de valores que se desenvolve com o crescimento do ciberespaço". O ciberespaço por sua vez é para Levy (2010), um sinônimo de rede ou "o novo meio de comunicação que surge da interconexão mundial dos computadores”.

Neste artigo situamos o estágio atual da Inteligência Artificial dentro das teorias da cibercultura discutidas por Rüdiger (2013). Busca-se compreender como se desdobra a relação de polarização em relação às perspectivas do trabalho numa Sociedade permeada pela Inteligência Artificial. Afinal a Inteligência Artificial libera a humanidade dos deuses pela posse do fogo, ou a escraviza pela busca eterna do conhecimento? Conforme escreve Levy (2010), "Nem a salvação, nem a perdição residem na técnica. Sempre ambivalentes, as técnicas projetam no mundo material nossas emoções, intenções e projetos".

\subsubsection{Prometeu}

Prometeu é personagem da obra Prometeu Acorrentado. Há várias versões do mito. A mais famosa é atribuída ao dramaturgo grego Ésquilo [Vernant 1991]. Prometeu sempre esteve ao lado dos homens [Stephanides 2004]. Queria proporcionar à Humanidade uma vida melhor. Esta ainda não tinha conhecimento do fogo. Por isso, roubou o fogo de Hefesto e o entregou aos homens. Além de entregar o fogo aos homens Prometeu ensinou-lhes uma série de ofícios e a superar toda a sorte de dificuldades. Embora Zeus tenha condenado Prometeu a ver o fim da Humanidade, a figura mítica do titã é usada para simbolizar uma visão associada à tecnofilia.

Segundo Rüdiger (2013), para os prometeicos “a técnica é uma força criada pelo homem e pela qual ele faz enormes sacrifícios, mas que em última instância, representa 
seu bem maior e a única forma de salvação intramundana”. Assim, o elogio da técnica se dá com a ascensão do capitalismo e por meio das revoluções industriais.

\subsubsection{Fausto}

Segundo Rüdiger (2013), a velocidade das mudanças e a suas consequentes imposições sobre a vida social, fez com que algumas expectativas sobre o progresso da técnica fossem revisadas. Assim, a tecnologia passou a ser vista como algo ameaçador que teria a possibilidade, inclusive, de extinguir a Humanidade. Fausto é o personagem do poema trágico escrito por Goethe. Há várias versões de Fausto ao longo da história, sendo a mais significativa a de Goethe no século XVI [Goethe 2003].

Segundo Godoy (2020), "Fausto simboliza a soberba da busca do poder pelo conhecimento (quero ficar muito erudito, perceber tudo o que há na terra, e tudo o que no céu se encerra, natureza e ciência, ao infinito)". O já erudito Doutor Fausto faz um pacto com Mefístoles pelo conhecimento, muito embora "suas inquietações transcendiam a premissa de que toda pessoa racional questiona periodicamente suas metas e motivos e as crenças que os sustentam" [Godoy 2020]. Mefístoles passa a ser o servo de Fausto, até que este admita um único prazer terreno. Fausto se apaixona e sucumbe ao plano de Mefístoles, tornando-se seu servo.

A história de Fausto serve como uma analogia aos efeitos danosos da exacerbação tecnológica e a busca desenfreada por velocidade e produção. $\mathrm{O}$ principal ponto a ser destacado aqui é o caráter ambivalente da tecnologia, pois "toda tecnologia tanto é um fardo como uma benção; não uma coisa ou outra, mas sim isto e aquilo" [Rüdiger 2013].

\section{O futuro do trabalho}

Como representação de visão prometeica do papel da Inteligência Artificial no mundo do trabalho, destacamos o recente artigo de Mary Sako [Sako 2020]. Para a autora, "um trabalho consiste em tarefas interrelacionadas, não de trabalhos que são automatizados por computadores". Sako (2020) separa as tarefas naquelas que podem ser automatizadas e naquelas que requerem a intervenção humana por meio da intuição, da criatividade e da persuasão. Estas qualidades, segunda a autora, são menos suscetíveis à automação.

Assim, numa dada profissão, algumas tarefas serão automatizadas e outras complementadas por esta automatização. Considera-se então que há uma potencialização daquela função desempenhada por um ser humano. Sako (2020) considera que novas tarefas são demandadas e que a associação destas aos empregos existentes ainda é uma incógnita. Novos postos trabalhos que serão criados poderão ser classificados em três tipos: treinadores, sustentadores e explanadores. Os treinadores serão importantes na configuração de robôs ensinando empatia e detecção de sarcasmo. Os sustentadores atuarão na verificação da qualidade de operação dos sistemas inteligentes. Já os explanadores serão responsáveis por analisar e explicar para o público leigo o funcionamento dos algoritmos utilizados nos sistemas inteligentes.

Sako (2020) também aduz que muitas das profissões permanecerão essencialmente humanas devido às questões éticas e por causa da normatização social. Para a autora assim como o trabalho artesanal foi desmantelado pela primeira revolução industrial, o trabalho profissional atual sofrerá uma desagregação em algumas das suas 
atividades. No caso de profissões licenciadas por conselhos de classe profissional, algumas tarefas poderão ser automatizadas, porém a responsabilidade permanecerá com o seu detentor. A necessidade de profissionais híbridos com conhecimentos em diversas áreas também é apontada como uma tendência pela autora [Sako 2020].

A perspectiva ética que envolve a Inteligência Artificial é uma tarefa árdua que envolve diferentes campos como a Filosofia, a Psicologia, a Matemática, a Computação, além do Direito e outros [Chao 2019], pois "a conduta inadequada de uma máquina pode gerar riscos imprevisíveis". Para Chao (2019) um dos maiores desafios no campo da ética em inteligência artificial é fazer com que esta aja de acordo com a vontade social que é múltipla. Esta questão é importante no caso do trabalho, pois as repostas automatizadas dadas por agentes que substituem os humanos podem não ter as nuances adequadas que atendam as expectativas sociais específicas para um dado ambiente. Análise e julgamento ainda são áreas de fronteira no campo da Inteligência Artificial.

Para Ionescu e Andronie (2019), os governos devem encorajar a criatividade e uma série de conhecimentos específicos de tecnologia como análise de dados. Para as autoras profissões como designers, especialistas em transformação digital e especialistas em Blockchain, além das relacionadas à Robótica estarão em alta a partir de 2022. A disrupção causada pelas novas tecnologias demandará o reaprendizado por parte dos trabalhadores e a criação de novos empregos para as novas gerações [Ionescu e Andronie 2019]. A interferência positiva dos governos será primordial para a readequação em termos de tarefas e até mesmo de profissões, pois políticas públicas deverão ser criadas para possibilitar a readequação das forças de trabalho existentes.

Para Cottey (2013) faz-se necessária uma mudança radical nos valores presentes na nossa cultura. $\mathrm{O}$ autor aduz ainda, que além de uma renda básica, é urgente a limitação da acumulação máxima. $\mathrm{O}$ acúmulo ilimitado se mostra antissocial e contra os valores de uma sociedade civilizada. O uso de máquinas e computadores, além de mudanças estruturais devem permitir a implementação de uma renda básica além de uma ressignificação do conceito de trabalho enquanto tarefa repetitiva passível de automação.

Para Murphy (2020), o uso de robôs durante a pandemia de COVID-19 mostra uma oportunidade negligenciada. Robôs estão sendo usados para auxiliar nas tarefas existentes e predominantemente humanas. Em situações anteriores como no desastre nuclear de Fukushima, os robôs existiam e não puderam ser amplamente utilizados devido a sua desatualização. A desinfecção de salas, o transporte e comida e a detecção de violação de regras de quarentena são algumas das atividades realizadas por estes equipamentos. Aqui temos, um exemplo concreto do que argumenta Sako (2020), pois os robôs estão sendo utilizados para automatizar algumas tarefas não suprimindo de forma absoluta o trabalhador humano.

\section{Conclusão}

O impacto da Inteligência Artificial no mundo do trabalho varia enormemente. Segundo Sako (2020) o número de postos de trabalhos substituídos pela automação poderá variar em 9\% (citando estudo da OEDC), 47\% de 702 ocupações (citando o estudo de Frey e Osborne) e 96\% citando diversos outros estudos atuais. Evans (2013) cita o estudo de Dominic Barton que diz que $40 \%$ dos postos de trabalho do Canadá irão desaparecer na próxima década. 
Não é uníssono o discurso sobre o mundo do trabalho na sua afetação pela Inteligência Artificial. Distinguem-se, principalmente, duas vertentes sobre o assunto. Uma positiva, que marcadamente vislumbra o que a Inteligência Artificial pode fazer em prol da Humanidade e outra negativa, preocupada com o impacto destruidor das novas tecnologias. À primeira associamos a visão prometeica e emancipatória, à segunda a visão fáustica e escravizadora.

Numa visão crítica que rompe o binarismo dessas visões surge uma abordagem que busca discutir criticamente o assunto. Esta visão mostra que "as tecnologias de informação não são função de um propósito social pré-determinado: são parte do contexto histórico em meio ao qual a vida é articulada" conforme ensina Rüdiger (2013).

Pelo que foi exposto no nosso artigo, sugerimos o aprofundamento no estudo das ações governamentais que propiciem uma transição de profissões que serão plenamente automatizadas para as que surgirem a partir desta automação. É no campo das políticas públicas que o Estado deve agir para enfrentar o problema que poderá ser gerado pela potente Indústria 4.0.

Embora não tenhamos explorado esta questão no nosso artigo, há vários estudos que sugerem a implementação de uma renda mínima para todos aqueles trabalhadores que vierem a ser atingidos pelo alto impacto da automatização. Esta renda garantirá o mínimo existencial para aquelas profissões mais atingidas. Outro campo que deverá sofrer muitas alterações é o da área da Educação, pois o modelo de mudanças rápidas e de profissões híbridas conforme asseverado por Sako (2020) deve fomentar sobretudo a criatividade, ainda pouco explorada na formação escolar.

As alterações geradas pela rápida expansão da automatização sobretudo aquelas que sobrevierem da Inteligência Artificial deverão ser amplamente implementadas espacialmente ou correr-se-á o risco de regiões serem altamente competitivas enquanto outras permanecerão no passado e na pobreza. Deve-se permitir o acesso aos frutos gerados pela tecnologia diminuindo a disparidade entre ricos e pobres. De forma sustentável deve-se erradicar a miséria ou colocar-se-á em xeque qualquer tentativa de chegarmos a uma Sociedade 5.0 e de bem-estar social. Esta só poderá ser alcançada mediante o fortalecimento dos regimes democráticos e do pleno acesso à tecnologia.

\section{Referências}

Chao, C-H (2019), Ethics Issues in Artificial Intelligence, In: International Conference on Technologies and Applications of Artificial Intelligence (TAAI), Kaohsiung, Taiwan.

Cottey, A. (2014), Technologies, culture, work, basic income and maximum income. In: AI and Society 29. Springer. Reino Unido.

Dignum, V. (2019). Responsible Artificial Intelligence: how to develop and use AI in a responsible way, Springer, $1^{a}$ edição. Suiça.

Ertel, W. (2017), Introduction to Artificial Intelligence, Springer, $2^{\mathrm{a}}$ edição, Reino Unido.

Evans, G-W. (2013), Artificial Intelligence: Where We Came From, Where We Are Now, and Where We Are Going, https://bit.ly/2yk384L, Acesso em 20-mar-2020. 
Godoy, A. (2018), "Fausto, o pacto com o diabo e a metáfora do arrependimento como salvação", In: Conjur, https://bit.ly/3btUVt0, Acesso em 19-mar-2020.

Goethe, W. J. (2003), Goethe Fausto, Tradução de António Feliciano de Castilho, W M Jackson Inc Editores, Brasil.

Ionescu, L. e Andronie, M. (2019). "The future of Jobs in the digital world", In: International Conference on Economic Sciences and Business Administration, Spiru Haret University, https://bit.ly/2ylv5Jt, Romênia.

Levy, P. (2010), Cibercultura, Editora 34, $3^{\mathrm{a}}$ edição. Brasil.

Merluzzi, O. (2019), "A Sociedade 5.0, a Indústria 4.0 e a distância que separa muitos países”, In: Revista Robótica, http://www.robotica.pt/PDF/ROB117/dossier.pdf, N 117, Acesso em 28-mar-2020.

Murphy et al. (2020). Robots have demonstrated their crucial role in pandemics - and how they can help for years to come. In: World Economic Forum, https://www.weforum.org/agenda/2020/05/robots-coronavirus-crisis. Acesso em 29jun-2020.

Roncati, J. et al. (2018). "O desafio dos Empregos na Quarta Revolução Industrial”, In: Automação e Sociedade: quarta revolução industrial, um olhar para o Brasil, Coordenado por Silva, E. et al. Editora Brasport. Brasil.

Rüdiger, F. (2013), As teorias da cibercultura: perspectivas, questões e autores, Editora Sulina, $2^{\mathrm{a}}$ edição. Brasil.

Sako, M. (2020), “Artificial Intelligence and the Future of Professional Work”, In: Communicatios of the ACM, Vol. 63, No 4, Estados Unidos.

Stephanides, M. (2004). Prometeu, os homens e outros mitos. Odysseus. Brasil.

Taulli, T. (2019), Introdução à Inteligência Artificial: uma abordagem não técnica, Editora Novatec, $1^{a}$ edição. Brasil.

Tchápek, K. (2012), A fábrica de rôbos. Editora Hedra, 1ª edição, Brasil.

Vernant, J-P. (1991), Mito e tragédia na Grécia antiga, Editora Brasiliense, Brasil. 